\title{
Portraying climate scenario uncertainties in relation to tolerable regional climate change
}

\author{
Mike Hulme*, Olga Brown
}

Climatic Research Unit, School of Environmental Sciences, University of East Anglia, Norwich N R4 7TJ, United Kingdom

\begin{abstract}
Analyses of the impacts of future anthropogenic climate change on environmental and social systems have been dominated by a 'top-down' approach. A climate change scenario is defined using output from one or more climate model experiments, the scenario is run through one or more environmental simulation models, and the impacts of the prescribed climate change evaluated. This approach places a considerable burden on the selection of which climate change scenarios should drive the impacts assessment. An alternative approach for assessing possible impacts of climate change follows a 'bottom-up' (or inverse modelling) approach. Here, the sequence of analysis steps is inverted. An assessment is made of what range of magnitudes and/or rates of regional climate change could be adapted to by an environmental or social exposure unit. The question is then asked of the climate scenario developer, how likely is it that future regional climate change will exceed these limits, and by when? Under what scenario or modelling assumptions will these limits be exceeded? And how do these future changes relate to current climate variability? In this paper we present a systematic approach for considering the effect of a set of scenario and modelling uncertainties on the likelihood of critical climate change being exceeded for particular exposure units. We present this assessment in the context of observed climate change over the last $100 \mathrm{yr}$ and illustrate the approach for the UK and for 2 thresholds of climate change. These are defined, very simplistically, in terms of summer mean temperature and rainfall and as such may nominally be regarded as relating to water resources in the UK. We argue that one of the strongest advantages of this approach is that it disarms those who wield climate change scenarios as though they were in some sense 'predictions' of future climate. By visualising the effects on realised future climate of different modelling assumptions and scenario uncertainties, we make more transparent the judgements that must be made in assessing the significance of climate change impacts on different regional exposure units.
\end{abstract}

KEY WORDS: Climate scenarios - Natural climate variability · Scenario uncertainties - UK climate . Climate modelling

\section{INTRODUCTION}

Analyses of the impacts of future anthropogenic climate change on environmental and social systems have been dominated by the 'top-down' approach summarised by the Intergovernmental Panel on Climate Change (IPCC) in 1994 (Carter et al. 1994). A climate change scenario is defined using output from one or more climate model experiments, the scenario is run through one or more environmental simulation models, and the impacts of the prescribed climate change evaluated. This approach places a considerable burden on the selection of which one, or more, climate change

\footnotetext{
*E-mail: m.hulme@uea.ac.uk
}

scenarios should drive the impacts assessment. A variety of criteria may be used in such a selection process (Smith \& Hulme 1996), but whatever the outcome there is an implicit assumption that the scenarios chosen are in some way normative or representative.

An alternative approach for assessing possible impacts of climate change would follow a 'bottom-up' approach, or adjoint method (Parry \& Carter 1989). Here, the sequence of analysis steps is inverted. An assessment is made of what range of magnitudes and/or rates of regional climate change could be adapted to by an environmental or social exposure unit. The question is then asked of the climate scenario developer, how likely is it that future regional climate change will exceed these limits? This allows an unbiased search to be made of the range of 'climate change 
space' defined by different emissions scenarios, climate sensitivities, or model-generated regional patterns of climate change. The impact assessor or scenario expert may still need to make some judgement about the relative likelihood of different scenario outcomes, but this judgement can be made more transparently and in the light of a more complete quantification of the future climate change space related to different sources of uncertainties.

This 'bottom-up' conceptual approach has been tentatively explored at a global scale through the inverse modelling of Alcamo \& Kreileman (1996) and their 'safe emissions corridors' and Wigley et al. (1996) and their stabilisation scenarios, and also by Parry et al. (1996). All 3 of these studies attempted to address Article 2 of the UN Framework Convention on Climate Change, namely what atmospheric concentrations of greenhouse gases, and hence what climate change, would be regarded as 'dangerous'. The climate change space illustrated in the latter study was defined only on the basis of global emissions uncertainties and only in one dimension, global-mean annual temperature change. In the present paper we illustrate how this approach could be extended in 3 ways. First, we apply the method at a regional scale and relate the study to a nominal regional climate change impact. Second, we utilise climate change space defined by uncertainties related to the climate sensitivity and to the regional patterns of climate change defined by global climate model (GCM) experiments, in addition to the emissions uncertainties illustrated by Parry et al. (1996). Third, we define the climate change space in 2 dimensions, mean temperature and rainfall, rather than using just temperature alone. This approach helps redefine the use that can be made of climate change scenarios derived from climate models, both simple and complex, and quantifies in a systematic way uncertainties in these scenarios which stem from different forcing, climate sensitivity and regional pattern outcomes. We argue that one of the strongest advantages of this approach is that it disarms those who wield climate change scenarios as though they were in some sense 'predictions' of future climate (Henderson-Sellers 1996) and makes more transparent the judgements that must be made in assessing the significance of climate change impacts on different regional exposure units.

We take a nominal example of a regionally aggregated exposure unit: water resources in the UK. An arbitrary judgement is made about what would be an 'acceptable' magnitude and rate of regional climate change to which this resource system could adapt without its viability being threatened. This 'acceptable' regional climate change is expressed in terms of our 2 key climate variables: mean temperature and precipitation (or rainfall in fact since the UK does not experience solid precipitation in summer). We then ask the question, how likely is it that regional climate change will fall within this threshold? We answer this question by interrogating a linked simple/complex climate model scenario generator (MAGICC/SCENGEN; Hulme et al. 1995a, b), which allows uncertainties in emissions scenarios, climate sensitivity and regional climate modelling to be quantified.

Added value is supplied to this interpretative judgement by overlaying the historic (100 yr) observed climate variability for these regions on the same climate change space used to portray future climate change. We also examine results from a recent transient global climate model experiment (HADCM2; Mitchell et al. 1995, Mitchell \& J ohns 1997). In this experiment, simulations forced by both greenhouse gas only and greenhouse gas plus aerosol scenarios have been completed, thus quantifying a further source of scenario uncertainty (aerosol-induced patterns of change). These simulations comprise 4-member ensembles, and within-ensemble differences illustrate the difficulties of signal definition at a regional scale.

Section 2 describes the sources of the observed data analysed, and the various models which contribute to the analysis. We also explain our choice of critical threshold for the selected region. In Section 3, the historic analysis is presented using $100 \mathrm{yr}$ of temperature and rainfall data in the UK. Section 4 then considers the range of future climate changes in the UK, first using results from equilibrium climate change experiments and, second, using results from ensemble realisations from a transient climate change experiment (HADCM 2). We conclude in Section 5 by discussing some of the considerations which require fuller investigation before the true value of this approach can be identified and whether or not the approach can be applied to real examples and in a diversity of sectors and regions.

\section{DATA SETS, CLIMATE MODELS AND CRITICAL THRESH OLDS}

The analysis presented here requires 3 broad categories of data or model results: observed regional climate data; results from simple climate models; and results from GCM climate change simulations. This section describes the sources for these data and models.

\subsection{O bserved data}

The monthly Central England Temperature record (Manley 1974, Parker et al. 1992) and the England and 
Wales Precipitation record (J ones \& Conway 1997) are used to describe the historic variations in summer mean temperature and rainfall over an area representative of central England. Although these records extend back to 1659 and 1766 respectively, we generally display only the $100 \mathrm{yr}$ of most recent data from 1896 to 1996. The domains of these data series are shown in Fig. 1.

\subsection{Climate models}

To calculate a range of future rates and magnitudes of global warming we use the simple climate model of Wigley \& Raper [1992 and updated; also called MAGICC (Model for the Assessment of Greenhouse gas Induced Climate Change); see Hulme et al. 1995a]. This model has been widely used by the IPCC in their Second Assessment Report and results used here are fully consistent with the projections discussed there (Kattenberg et al. 1996, IPCC 1997). MAGICC consists of a suite of gas cycle models and an upwelling-diffusion energy balance model, with separate land and ocean boxes with northern and southern hemispheres.

The regional values for the UK of the mean temperature and rainfall changes calculated by a range of GCM experiments are extracted using Version 2.1 of the

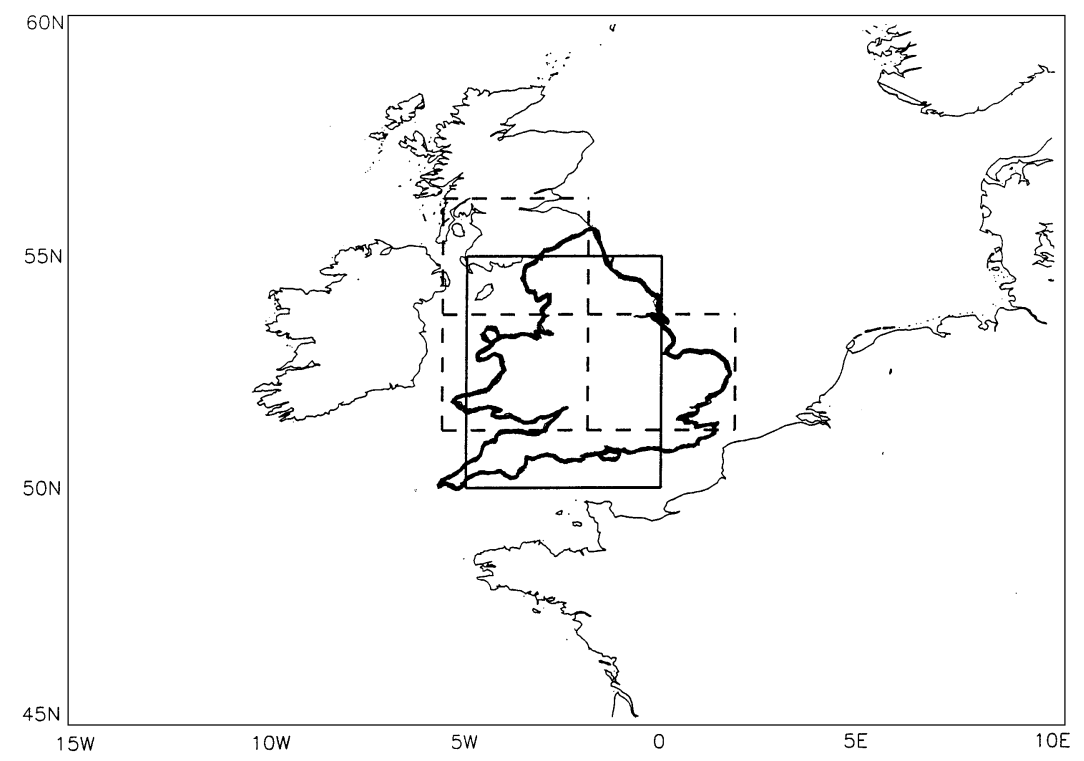

Fig. 1. Geographical domains of the observed and modelled climate data series for the UK. Bold box shows the grid for which data from SCENGEN were extracted, and the dashed boxes show the model grid for which data were extracted from the HADCM 2 transient simulations. The emboldened coastline for the UK demarcates the domain of the observed England and Wales time series

Table 1. The 14 GCM climate change experiments used in SCENGEN and in this paper. Eq.: equilibrium slab-ocean experiment; Tr.: transient fully coupled ocean-atmosphere experiment. For the experiments marked *only the greenhouse gas forced simulations were used

\begin{tabular}{|c|c|c|c|c|}
\hline \multirow[t]{2}{*}{ GCM acronym } & \multirow{2}{*}{ Date and type } & \multicolumn{2}{|c|}{ Spatial resolution $\left({ }^{\circ}\right)$} & \multirow[t]{2}{*}{ Source } \\
\hline & & Lat. & Long. & \\
\hline GISS & 1983, Eq. & 8.0 & 10.0 & Hansen et al. (1984) \\
\hline GFDL & 1986, Eq. & 4.5 & 7.5 & Wetherald \& M anabe (1986) \\
\hline KLO & 1987, Eq. & 5.0 & 7.5 & Wilson \& Mitchell (1987) \\
\hline OSU & 1989, Eq. & 4.0 & 5.0 & Schlesinger \& Zhao (1989) \\
\hline LLNL & 1989, Eq. & 4.0 & 5.0 & W. L. Gates (pers. comm. 1990) \\
\hline UKHI & 1989, Eq. & 2.5 & 3.75 & Mitchell et al. (1989) \\
\hline ECHAM 1 & 1990, Tr. & 5.625 & 5.625 & Cubasch et al. (1992) \\
\hline CSIRO9 & 1992, Eq. & 3.2 & 5.625 & McGregor et al. (1993) \\
\hline BMRC & 1992, Eq. & 3.2 & 5.625 & M cAvaney et al. (1991) \\
\hline $\mathrm{CCC}$ & 1992, Eq. & 3.75 & 3.75 & Boer et al. (1992) \\
\hline UKTR & 1992, Tr. & 2.5 & 3.75 & M urphy \& M itchell (1995) \\
\hline HADCM 2* & 1995, Tr. & 2.5 & 3.75 & Mitchell et al. (1995) \\
\hline CSIRO09Mk2 & 1995, Eq. & 3.2 & 5.625 & Dix \& Hunt (1995) \\
\hline ECHAM 3* & 1995, Tr. & 5.625 & 5.625 & Kattenberg et al. (1996) \\
\hline
\end{tabular}




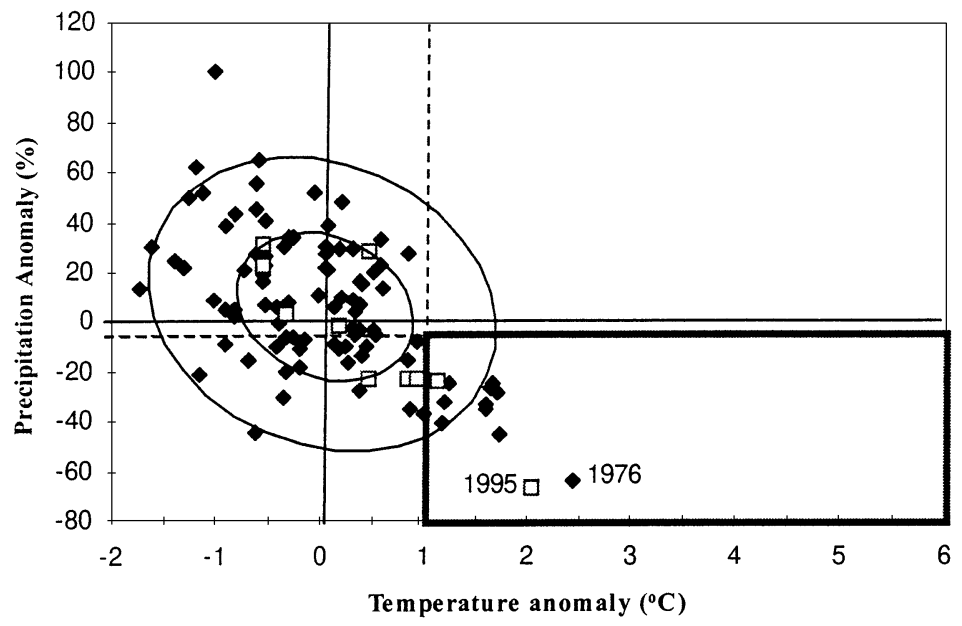

Fig. 2. Yearly anomalies, with respect to average 1961-1990 climate, of summer mean temperature and rainfall for 1896 to 1996 for the UK derived from the Central England Temperature record and the England and Wales Precipitation record. The $1 \sigma$ and $2 \sigma$ limits calculated on 1961-1990 data are shown as concentric ellipses, oriented along the best-fit regression between temperature and precipitation. On this, and all subsequent plots, the a priori defined 'critical' climate change space for UK water resources is shown by the bold line as exceeding $1^{\circ} \mathrm{C}$ warming and $5 \%$ drying. The last 10 years' data are shown as squares ments in which the effects on climate of both greenhouse gases and sulphate aerosols have been considered. This is the transient climate change experiment completed by the Hadley Centre in 1995 (HADCM 2) and reported in Mitchell et al. (1995), Mitchell \& J ohns (1997) and J ohns et al. (1997). This experiment consisted of a multi-century control (unforced) simulation and 4 sets of perturbed simulations over the period 1861 to 2100 , each set consisting of 4 different realisations with the same forcing but different initial conditions. For our purposes we use monthly time series extracted from the first $240 \mathrm{yr}$ of the control simulation and monthly time series extracted from the period 1961 to 2100 in 2 sets of the perturbed simulations. The forcing in the 2 perturbed ensembles used here approximates, respectively, the greenhouse gas only and the greenhouse gas plus sulphate aerosol forcing represented by the IS92a emissions scenario of the IPCC (Leggett et al. 1992). Data were extracted from these simulations for the 3 HADCM 2 land grid boxes over the UK, a domain shown in Fig. 1. a common $5^{\circ}$ latitude/longitude grid using a Gaussian space-filtering routine. The results for the UK are extracted from one $5^{\circ}$ SCENGEN box (Fig. 1). Since the SCENGEN values have been interpolated from variable model grids however, these SCENGEN estimates are representative of a broader spatial domain than represented by this gridbox alone. The issue of the appropriate spatial domain for estimating regional climate change scenarios is returned to later in the paper.

SCENGEN displays GCM-derived patterns of climate change standardised according to the globalmean temperature change of each respective GCM experiment and then re-scaled according to the global warming calculations of MAGICC for any given time period. This 'GCM scaling method' was first proposed by Santer et al. (1990), subsequently developed and applied elsewhere (e.g. Rotmans et al. 1994), and more recently investigated thoroughly by $\mathrm{Mitchell}$ et al. (1998). The attraction of this scaling method is that GCM patterns of climate change can be displayed and inter-compared after eliminating the effects of different model sensitivities and different experimental forcing scenarios. The key assumption that lies behind this method is that equilibrium GCM experiments generate a robust anthropogenic climate change signal, a signal that is linearly related to the global-mean temperature. The implications of this assumption have been explored by Mitchell et al. (1998).

In addition to SCENGEN, we also use more detailed results from one of these GCM climate change experi-

\subsection{Regional exposure units}

The example of a critical climate change threshold we have chosen to illustrate our approach relates nominally to water availability in the UK. We arbitrarily define the critical climate change threshold for this sector to be a $1^{\circ} \mathrm{C}$ summer (J une, J uly and August; J J A) warming combined with a $5 \%$ decrease in summer rainfall. This is a deliberately simple and arbitrary choice and excludes for the moment any consideration of time-scale. Defining what may or may not be realistic critical thresholds is not the objective of this paper. In our concluding discussion we illustrate alternative ways of defining critical thresholds within the context of our methodology. The choice of appropriate thresholds needs of course to be rooted in results from sensitivity and vulnerability studies performed for this sector [e.g. see Arnell et al. (1994) for the UK], and would also require consideration of evaporation changes and options for management intervention.

\section{HISTORIC CHANGES IN UK SUMMER CLIMATE}

We start our analysis by representing the historic variability in UK climate through 2 climate variables: summer mean temperature and summer rainfall. Fig. 2 shows the scatter of years in this 2-dimensional 'cli- 
mate change space', where each year is located by its temperature and rainfall anomaly with respect to the average 1961-1990 climate. The interannual variability of these climate anomalies is summarised by the $1 \sigma$ and $2 \sigma$ limits that are shown as concentric ellipses in Fig. 2 (see also Table 2). The ellipses are oriented around the axis of a least-squares regression fit to the data $\left(R^{2}=0.39\right)$, where the slope of this axis reflects the interdependence of summer temperature and rainfall in the UK. These variability limits isolate individual summers that are extreme with respect to average UK summer climate. For example, 1995 and 1976 fall well outside the $2 \sigma$ limits with anomalies greater than $+2^{\circ} \mathrm{C}$ mean temperature and $-60 \%$ rainfall. The last 10 individual summers - 1987 to 1996 - are identified separately in this plot, a sub-sample that suggests a recent tendency for summer warming and drying (see also Fig. 3). Six of these 10 summers have been warmer and drier than the 1961-1990 average and only 3 of them cooler and wetter.

Also marked in Fig. 2 is the domain in this climate change space that we have defined a priori as 'critical', namely anomalies that are greater than $+1^{\circ} \mathrm{C}$ in mean temperature and less than $-5 \%$ in rainfall. Although several (in fact 13) individual summers fall within this 'critical' space, it is not appropriate to talk about 'critical' climate change occurring since these are isolated years; there is a difference between a few individual extreme years exceeding a threshold and an entire climate regime shifting beyond some critical limit. For this reason we suppress the high frequency variability of summer climate in the UK by applying a $30 \mathrm{yr}$ lowpass Gaussian filter to the values shown in Fig. 2. Thirty years is chosen in keeping with the climatological convention of a World M eteorological Organisation (WMO) 'normal period' climate. Thirty years is also a reasonable period for depicting medium-low frequency climate variability. This filtering yields $71 \mathrm{cli}$ matological (overlapping $30 \mathrm{yr}$ average) anomalies with 1961-1990 climate represented as the point $(0,0), 1896-1925$ climate as $\left(-0.26^{\circ} \mathrm{C},+6.9 \%\right)$ and
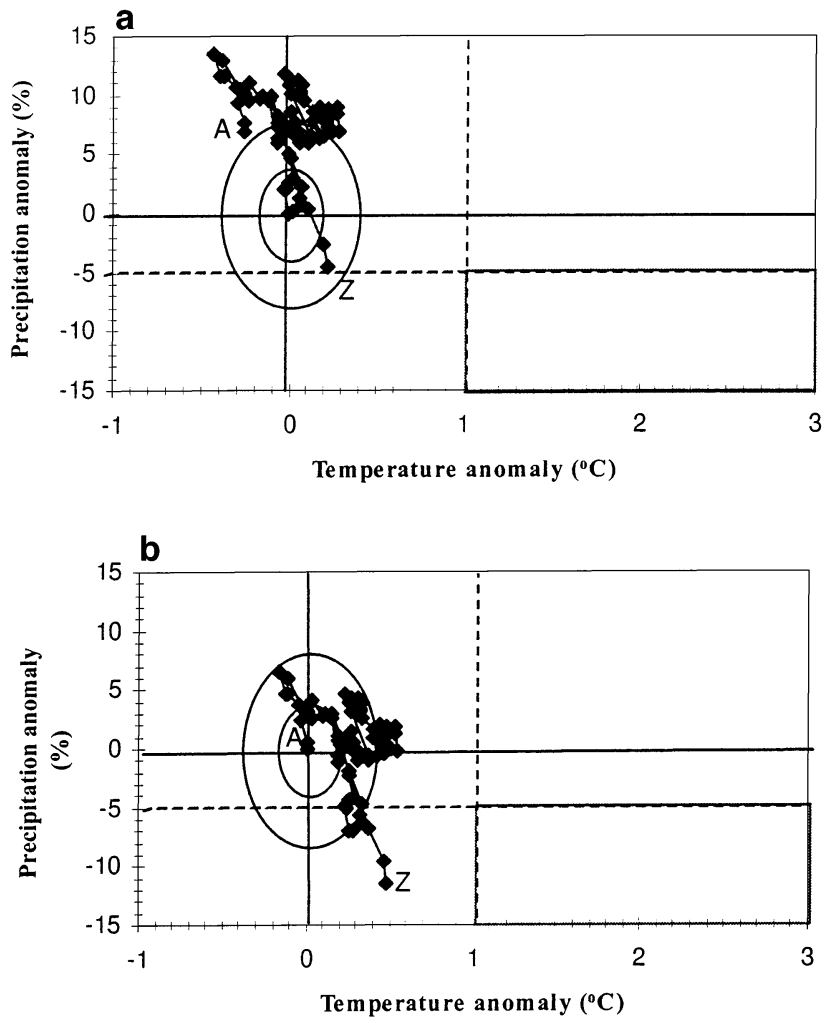

Fig. 3. Time evolution of $30 \mathrm{yr}$ filtered climates from 1896-1925 (point 'A') to 1967-1996 (point 'Z') for the same data as shown in Fig. 2, (a) with respect to average 1961-1990 climate, and (b) with respect to average 1896-1925 climate. The $1 \sigma$ and $2 \sigma$ limits of the full $30 \mathrm{yr}$ filtered series are plotted as concentric ellipses centred on average 1961-1990 or 1896-1925 climate

1967-1996 climate as $\left(+0.22^{\circ} \mathrm{C},-4.5 \%\right)$. The standard deviation limits shown in this filtered plot (Fig. 3) are the $1 \sigma$ and $2 \sigma$ limits of the full series of overlapping $30 \mathrm{yr}$ climates, centred on the 1961-1990 climate. (These medium-low frequency variability ellipses are not aligned along a regression axis since the $R^{2}$ between $30 \mathrm{yr}$ filtered temperature and rainfall is substantially less at only 0.18 .) The variability of $30 \mathrm{yr}$ cli-

Table 2. Interannual and $30 \mathrm{yr}$ filtered standard deviations $(\sigma)$ for summer mean temperature and rainfall over 'central England' defined from observations (1896 to 1996; or 1787 to 1996 for non-overlapping periods) and from model simulations (240 yr of HADCM 2 control simulation). The $\mathrm{R}^{2}$ value is the variance explained when a least-squares linear regression model is fitted to the temperature and rainfall values

\begin{tabular}{|lrrrr|}
\hline & $\mathrm{n}$ & $\mathrm{R}^{2}$ & $\sigma$ mean temp. $\left({ }^{\circ} \mathrm{C}\right)$ & $\sigma$ rainfall $(\%)$ \\
\hline Observed interannual & 100 & 0.39 & 0.84 & 29.4 \\
Modelled interannual & 240 & 0.09 & 1.00 & 23.3 \\
Observed overlapping 30 yr & 71 & 0.18 & 0.17 & 3.7 \\
Modelled overlapping 30 yr & 211 & 0.06 & 0.08 & 3.7 \\
Observed non-overlapping 30 yr & 7 & 0.06 & 0.23 & 5.7 \\
Modelled non-overlapping 30 yr & 8 & 0.00 & 0.15 & 4.4 \\
\hline
\end{tabular}


mates is clearly much reduced compared to the interannual variability shown in Fig. 2 (see also Table 2).

When these filtered values are plotted (Fig. 3a), the medium-low frequency time evolution of summer climate in the UK over the last $100 \mathrm{yr}$ can be traced (from $A \rightarrow Z$ ). This confirms the suggestion made above about a tendency for recent summer warming and drying. The most recent $30 \mathrm{yr}$ period (1967 to 1996) has clearly been drier than any other observed climate, although not quite as warm as the summer climates of the 1920s to 1940s. Summer climate in the UK has not, however, crossed either of the 'critical' thresholds established for water resource impacts, although it is close to the rainfall threshold.

These medium-low frequency climate anomalies are expressed with respect to the average 1961-1990 climate. Other choices of baseline period from which to measure climate change could of course be made. Fig. 3b illustrates the effect of altering the baseline period from 1961-1990 to 1896-1925 (i.e. the beginning of our period of analysis), which represents a climatic shift of $-0.26^{\circ} \mathrm{C}$ in mean temperature and $+6.9 \%$ in rainfall. When expressed with respect to the early twentieth century climate, the evolution of summer climate in the UK is seen to be moving closer to our predefined 'critical' change of $1{ }^{\circ} \mathrm{C}$ warming and $5 \%$ drying. Thus $1967-1996$ is $+0.48^{\circ} \mathrm{C}$ warmer and $11.4 \%$ drier than 1896-1925, although this change has taken 7 decades to be realised.

The Central England Temperature (CET) and England and Wales Precipitation (EWP) series both extend further back than 1896 (to 1659 for CET and to 1766 for EWP), which allows a longer-term perspective of sum-

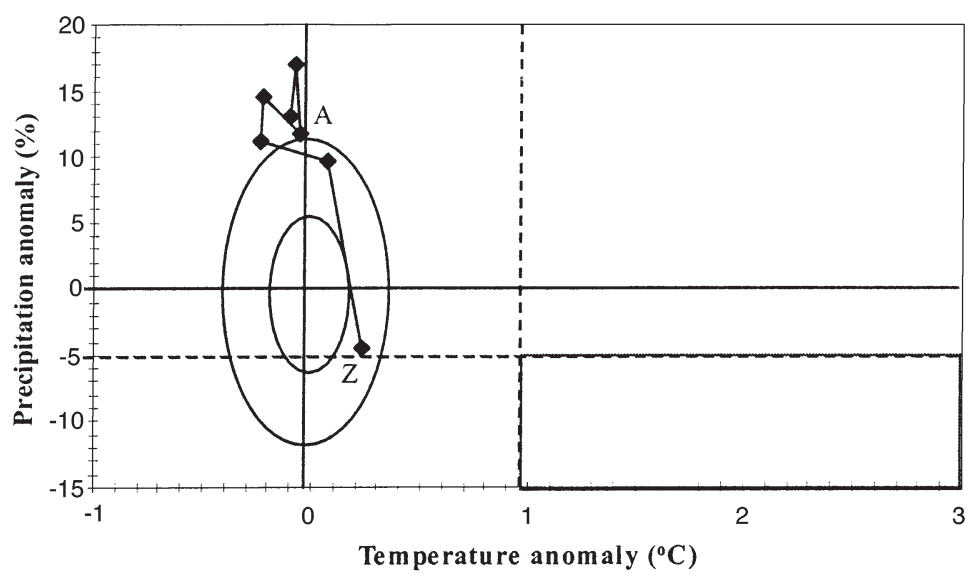

Fig. 4. Time evolution of non-overlapping $30 \mathrm{yr}$ filtered summer climates from 1787-1816 (point 'A') to 1967-1996 (point ' $Z$ ') for Central England Temperature and England and Wales Precipitation with respect to average 1961-1990 climate. The $1 \sigma$ and $2 \sigma$ limits of the 7 non-overlapping $30 \mathrm{yr}$ climates are plotted as concentric ellipses centred on average 1961-1990 climate and are slightly larger than for the overlapping $30 \mathrm{yr}$ climates of the last $100 \mathrm{yr}$ (Table 2) mer climate variability in the UK to be gained. Fig. 4 plots the evolution of UK summer climate using 7 nonoverlapping $30 \mathrm{yr}$ climates from 1787-1816 (A) to 1967-1996 (Z), expressed with respect to average 1961-1990 climate. The standard deviations of these 7 non-overlapping $30 \mathrm{yr}$ climates are slightly higher than for the overlapping climates of the last $100 \mathrm{yr}$, although the relationship between temperature and rainfall is weaker (Table 2). The recent trend towards warming and drying evidenced in Fig. 3 is reinforced and, in the context of the last $210 \mathrm{yr}$ of UK summer climate variability, becomes more significant.

\section{FUTURE CHANGES IN UK SUMMER CLIMATE}

\subsection{Equilibrium changes by 2050}

We now turn our attention to future climate change over the UK as simulated by a sample of GCM s forced by increased concentrations of greenhouse gases (and in one case also by sulphate aerosols). Fig. 5 plots the mean temperature and rainfall changes extracted from SCEN GEN for UK summer climate by a period centred on the year 2050 as simulated by the 14 GCM experiments listed in Table 1. As with the observations, these changes are again expressed with respect to average 1961-1990 climate. The magnitudes of these GCM derived changes are standardised on a greenhouse gas forced global-mean warming of $1.38^{\circ} \mathrm{C}$ by 2050 using the SCENGEN scaling method. This global warming figure is obtained from M A GICC using the IS92a emissions scenario (Leggett et al. 1992), default model parameters (i.e. a climate sensitivity of $2.5^{\circ} \mathrm{C}$ and other values following IPCC 1995; see Kattenberg et al. 1996), but constant sulphate aerosol forcing beyond 1990.

Each of these climate changes is derived from between 10 and $30 \mathrm{yr}$ of GCM simulated climate and thus represents a mediumlow frequency change in climate. The scatter of points in this climate change space is wide, ranging from 0.8 to $2^{\circ} \mathrm{C}$ for summer mean temperature change and between -9 and $+10 \%$ for summer rainfall change. The 3 most recent experiments of the 14 sampled here (ECHAM3, HADCM 2 and CSIRO$09 \mathrm{M} \mathrm{k2}$ ) are marked by name in Fig. 5 and these 3 experiments span the full range of simulated rainfall changes. There is little evidence here therefore that more recent GCM experiments are converging on agreed regional patterns of rainfall change.

These simulated climate changes are extracted from only one realisation of the 
respective GCM experiments and represent a realised change in mean climate by the year 2050. No information is displayed which sets these changes against the background level of natural variability and hence attributing significance to these changes is difficult. For one of these experiments (HADCM2), however, we plot the modelsimulated $1 \sigma$ and $2 \sigma$ limits for the sequence of overlapping $30 \mathrm{yr}$ filtered climates simulated in $240 \mathrm{yr}$ of the experiment's control (i.e. unforced) integration. These modelderived natural variability limits are quite similar to those calculated from the observations (Table 2), at least for rainfall if not for temperature.

Applying these model-derived natural variability limits suggests that, even at the $1 \sigma$ level, the SCENGEN-derived HADCM 2 rainfall change by 2050 of $+1.6 \%$ cannot be regarded as statistically meaningful. Given that some of the other GCM rainfall changes derive from only a $10 \mathrm{yr}$ simulated climate sequence (averaging periods that will have a higher standard deviation than the $30 \mathrm{yr} \mathrm{lim}$ its shown here), few of the summer rainfall changes simulated by the GCM s over the UK are likely to be significant. This large modelled and observed natural variability in UK summer rainfall, relative to the GCMderived climate change rainfall signals, does have a further consequence for the likelihood of 'critical' climate change. Although only 2 of the 14 GCM simulations (ECHAM 3 and GFDL) yield a mean climate change which falls within the 'critical' limits defined earlier, when combined with modelderived natural variability a large majority of the experiments may nevertheless yield $30 \mathrm{yr}$ climates which do fall within the critical zone. For example, if the HADCM 2 variability ellipses are applied to each of the other 13 climate change simulations, then a different proportion of the resulting ellipses would fall inside the 'critical' climate change space. Simulated anthropogenic temperature change, together with natural rainfall variability alone (i.e. no anthropogenic rainfall signal), may quite conceivably take UK climate into a domain defined here as 'critical' for water resources. Of course different climate models to HADCM 2 may yield different estimates for natural variability, but since HADCM 2 agrees quite well with the observed variability (Table 2 ) we seem justified to use these model estimates.

Also plotted in Fig. 5 is the simulated climate change for the HADCM 2 simulation in which sulphate aerosol forcing was combined with greenhouse gas forcing

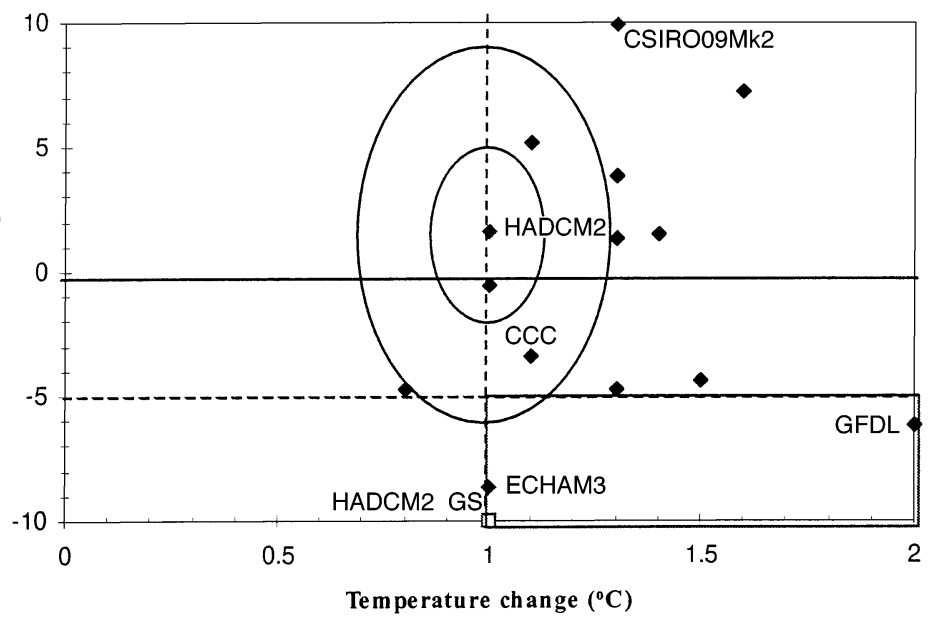

ig. 5. Mean summer temperature and rainfall change for the UK with respect to 1961-1990 simulated by 14 GCM greenhouse gas forced climate change experiments (see Table 1) and scaled to a 2050 global arming of $1.38^{\circ} \mathrm{C}$ (estimate derived from MAGICC assuming IS92a missions scenario, a climate sensitivity of $2.5^{\circ} \mathrm{C}$, default model parameer settings and constant aerosol forcing beyond 1990). Data extracted from SCENGEN. The 3 named simulations (ECHAM 3, CSIRO09Mk2 nd HADCM 2) represent the 3 most recent experiments. The CCC xperiment is also named and is used in Fig. 6. Also plotted are the changes simulated by the combined greenhouse gas and aerosol forced mulation of HADCM 2 (HADCM 2 GS) for the $30 \mathrm{yr}$ centred on the simlated year 2031. This is the period by which the greenhouse-gas-only orced simulation of HADCM 2 had warmed globally (with respect to 961-1990) by $1.38^{\circ} \mathrm{C}$. Also shown are the $1 \sigma$ and $2 \sigma$ limits of $30 \mathrm{yr}$ filered climate as simulated by $240 \mathrm{yr}$ of the unforced control integration f the HADCM 2 experiment. These limits are centred on the HADCM 2 imate change location to indicate the uncertainty that relates to $30 \mathrm{yr}$ time-scale natural variability

(Mitchell et al. 1995, Mitchell \& J ohns 1997). This result suggests that the effect of sulphate aerosols on UK summer rainfall by the middle of next century is to reduce rainfall totals by about $10 \%$ (cf. the greenhouse-gas-only forced result for HADCM 2 which yields a very slight wetting; but see Section 4.2 later). The inclusion of aerosols should also slow down the rate of greenhouse gas forced warming. This relative cooling is not evident in Fig. 5-both of the HADCM 2 scenarios warm equally by about $1^{\circ} \mathrm{C}-$ a result that is probably due to the effect of different natural interdecadal temperature variability in these 2 simulations.

Fig. 5 depicts only 2 sources of uncertainty in simulations of future climate change, namely the different regional patterns of climate change simulated by different GCM experiments and the effects of introducing sulphate aerosol forcing. There are 2 further important sources of uncertainty in assessing the range of possibilities for future regional climate change-the effect of different forcing (emissions) scenarios and the effect of different values of the climate sensitivity. As stated above, Fig. 5 assumes only 1 emissions scenario (IS92a) and only 1 value for the climate sensitivity $\left(2.5^{\circ} \mathrm{C}\right)$. 


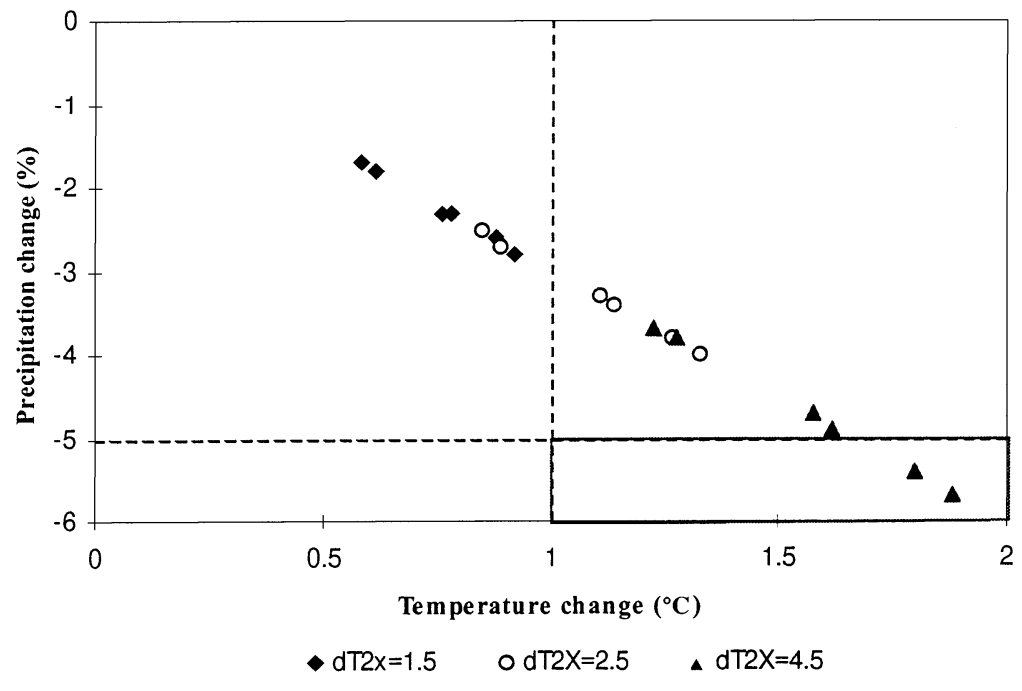

Fig. 6. Mean summer temperature and rainfall change for the UK with respect to 1961-1990 simulated by the CCC GCM greenhouse gas forced climate change experiment (see Table 1 ) and scaled to a range of global warming estimates for 2050 derived from MAGICC. This range of estimates uses the 6 IS92 emissions scenarios (IS92 a to f) and 3 different climate sensitivities (dT2X): $1.5^{\circ} \mathrm{C}, 2.5^{\circ} \mathrm{C}$ and $4.5^{\circ} \mathrm{C}$ (with default model parameter settings and constant aerosol forcing beyond 1990)

Both of these are mid-range assumptions according to IPCC 1995, but there are a range of other possibilities. We therefore took all 6 IS92 emissions scenarios (IS92a to f; see Leggett et al. 1992 and Kattenberg et al. 1996) and 3 different values of the climate sensitivity $(1.5,2.5$ and $4.5^{\circ} \mathrm{C}$ ) and simulated a range of global warming rates using MAGICC. For this part of the analysis we again hold sulphate aerosol forcing constant at 1990 levels. These 18 simulations yield a range of global warming values by 2050 (with respect to 1961-1990) of about $0.7^{\circ} \mathrm{C}$ (IS92C, $1.5^{\circ} \mathrm{C}$ sensitivity) to $2.3^{\circ} \mathrm{C}$ (IS92e, $4.5^{\circ} \mathrm{C}$ sensitivity), a range in which our previously used value of $1.38^{\circ} \mathrm{C}$ falls somewhere in the middle.

What effect does this range of global warming rates have on the UK summer climate change shown in Fig. 5? We can quantify this effect by scaling the standardised regional patterns of climate change derived from different GCM experiments by the different global warming values derived from MAGICC. We choose the CCC experiment (see Table 1) to illustrate this. Fig. 6 shows the scatter of points, each of which represents 1 realisation of the combined emissions and climate sensitivities applied to the CCC pattern of change. Thus the high end of the range, emissions scenario
IS92e with a $4.5^{\circ} \mathrm{C}$ sensitivity, yields a 'critical' climate change of $1.9^{\circ} \mathrm{C}$ summer warming and $5.7 \%$ drying, whereas IS92C and a low sensitivity of $1.5^{\circ} \mathrm{C}$ yields a 'non-critical' change of $0.6^{\circ} \mathrm{C}$ warming and $1.7 \%$ drying. This scatter of climate change realisations is linear since the ratio of mean temperature to rainfall change is fixed by the CCC experiment and the different global warming rates simulated by MAGICC for 2050 are simply scaling this ratio.

We are now in a position to combine our estimates of future climate change (Figs. $5 \& 6$ ) with the observed changes in UK summer climate (Fig. 3). This is shown in Fig. 7 using the 30 yr filtered observations with respect to 1961-1990. We now can see 2 things clearly. First, the range of observed changes in (30 yr averaged) rainfall during the twentieth century virtually spans the simulated range of changes by year 2050 ( -5 to $+14 \%$ observed; -9 to $+10 \%$ simulated). Second, however, the simulated changes in mean temperature fall well beyond those observed to date. Even if we take the low forcing scenario and low sensitivity realisation applied to the CCC-derived pattern, the future summer temperature of the UK by 2050 falls well outside the historic range observed over the last $100 \mathrm{yr}$. Despite this significant temperature change, relatively few of the future realisations of climate change fall in the range defined a priori as 'criti-

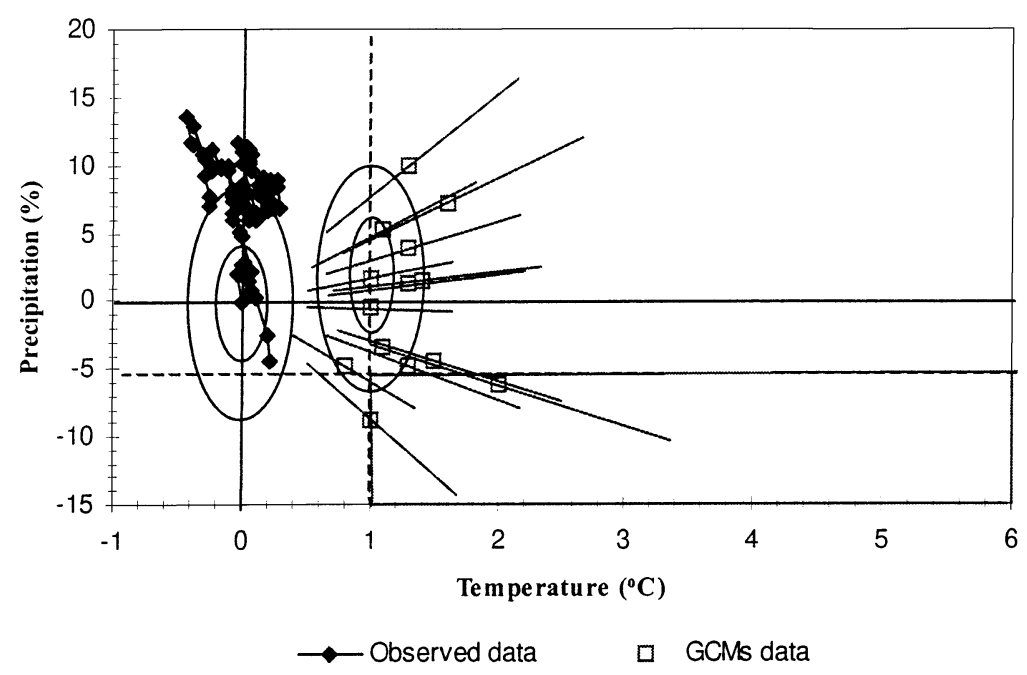

Fig. 7. Superimposition of data shown in Figs. 3a, 5 and 6, together with uncertainty lines equivalent to that shown for CCC in Fig. 6 added for all 14 GCM simulated changes 


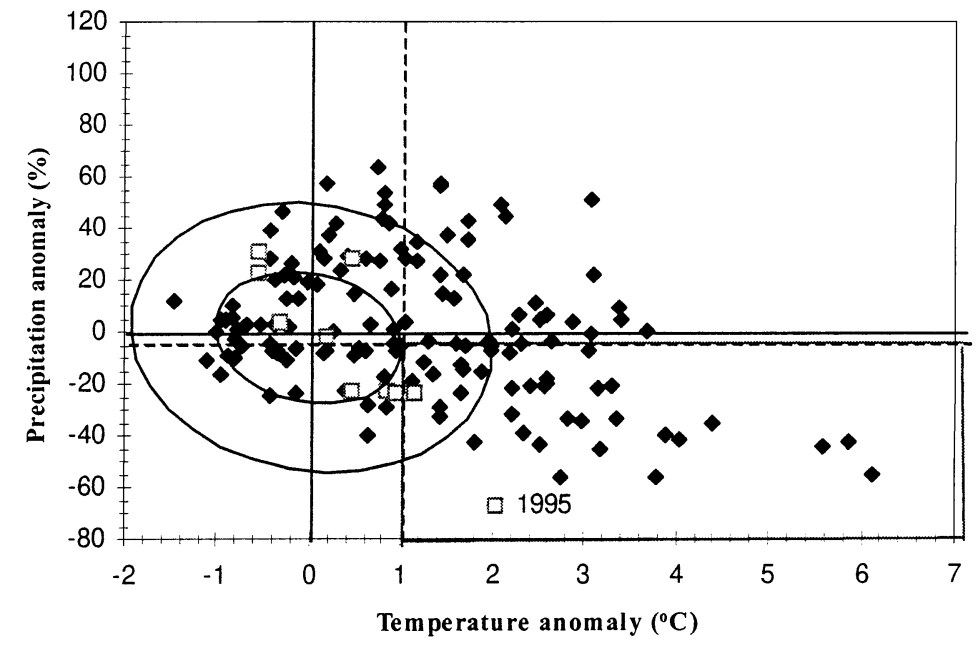

Fig. 8. Yearly anomalies, with respect to model-simulated 1961-1990 climate, of summer mean temperature and rainfall for model-simulated years 1961 to 2099 derived from the first realisation of the greenhousegas-only forced HADCM 2 simulation. Average of $3 \mathrm{GCM}$ boxes centred over the UK and shown in Fig. 1 . The $1 \sigma$ and $2 \sigma$ limits shown are those calculated from $240 \mathrm{yr}$ of the control integration of HADCM 2 and are aligned along a least-squares regression line relating temperature and rainfall. These limits are very similar to those observed for 1961-1990 climate (Table 2). The last 10 summers of observed anomalies (1987 to 1996) are plotted as open squares and 1995 summer is identified
The standard deviation limits shown here are the $1 \sigma$ and $2 \sigma$ for interannual summer climate extracted from $240 \mathrm{yr}$ of the model control integration. As in Fig. 2 for interannual climate variability, we align these ellipses along the best-fit regression line between modelsimulated summer temperature and rainfall. [The $R^{2}$ value of this model-derived regression line is only 0.09 , substantially less than that observed (0.39), suggesting that some significant real-world interdependency between summer temperature and rainfall is not captured by the model.] Clearly, there is a shift in the yearly anomalies towards the warm end of the climate change space, although relatively little change occurs over time in the rainfall dimension. Many of these twenty-first century simulated summers continue to fall within the unforced standard deviation limits and, conversely, at least some observed years will remain exceptional with respect to rainfall anomalies. For example, no future simulated year yields a summer rainfall anomaly as extreme as 1995 (plotted on Fig. 8) or 1976.

As with the observations, we now filter these yearly anomalies using a $30 \mathrm{yr}$ low-pass cal' for UK water resources. It should be noted here, however, that we have defined 'critical' climate change in terms of both temperature and rainfall. In some cases it may be more beneficial to explore the sensitivities of each variable separately. filter and examine the time evolution of UK summer climate as simulated by the first realisation of the HADCM 2 greenhouse gas forced experiment (Fig. 9). The general warming tendency is now clear such that by the end of the simulation period (i.e. average

\subsection{Transient changes}

The future climate changes described above are derived either from equilibrium climate change simulations or from $30 \mathrm{yr}$ averages extracted from transient GCM simulations. They do not reveal information about future inter-decadal climate variability nor about the evolution of climate over time. In this final section we explore these 2 issues using direct results from the HADCM 2 climate change experiment.

We start by showing the year-by-year anomalies in our climate change space for UK summer climate for each year from 1961 to 2099 in the first ensemble member of the greenhouse-gas-only forced HADCM 2 simulation, again with respect to average (model-calculated) 1961-1990 climate (Fig. 8). These data are averaged from the 3 HADCM 2 land gridboxes shown in Fig. 1.

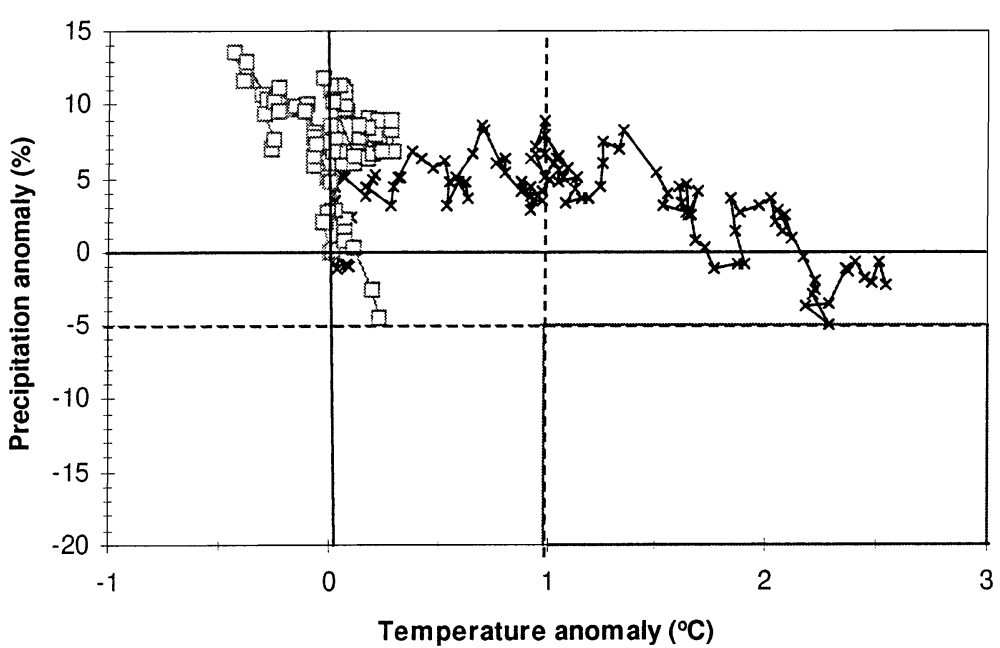

Fig. 9. Time evolution (left to right) of overlapping $30 \mathrm{yr}$ filtered climate anomalies with respect to model-simulated average 1961-1990 climate for 1961-1990 to 2070-2099 for the same HADCM 2 data as shown in Fig. 8. The observed overlapping $30 \mathrm{yr}$ filtered climate anomalies (ending in 1967-1996) are also plotted as open squares (cf. Fig. 3a) 


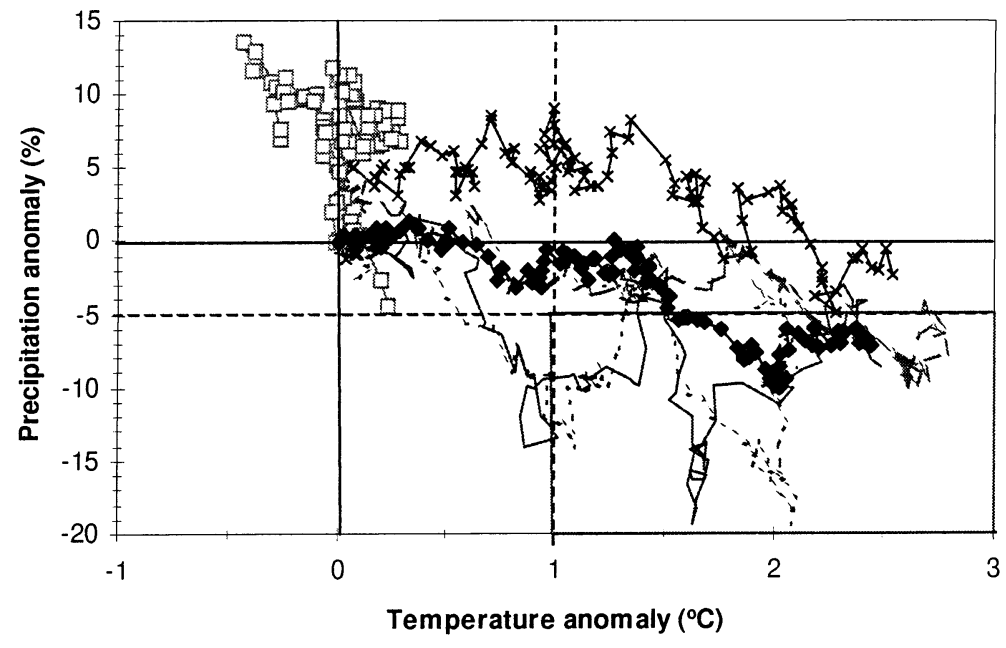

Fig. 10. Time evolution (left to right) of overlapping $30 \mathrm{yr}$ filtered climate anomalies with respect to model-simulated average 1961-1990 climate for 1961-1990 to 2070-2099 for each of 4 ensemble realisations $(x-x,---,---$, ----) for the greenhouse-gas-only forced HADCM 2 experiment. The data shown in Fig. 9 is the first ensemble member. The evolution of the ensemble-mean is shown as the line with filled diamonds. The observed overlapping $30 \mathrm{yr}$ filtered climate anomalies (ending in 1967-1996) are also plotted as open squares (cf. Fig. 3a)

2070-2099 climate) UK summers are about $2.6^{\circ} \mathrm{C}$ warmer than the 1961-1990 average. The evolution in summer rainfall is much less clear with relatively small $(5 \%)$ increases in summer rainfall during the early decades of next century, followed by a return to levels more typical of average 1961-1990 climate, and, by the end of next century, slight (5\%) decreases. Fig. 9 also includes the observed $30 \mathrm{yr}$ climates of the last $100 \mathrm{yr}$. This shows that although the current trend towards summer drying is not reproduced in the greenhousegas-only forced HADCM 2 simulation in the early decades of next century, the longer-term response of this HADCM 2 simulation is for a summer drying. With regard to our 'critical' climate change space, only a small number of model-simulated future $30 \mathrm{yr}$ climates fall inside this 'critical' domain by the end of next century, namely the climates centred around the 2070s.

We next examine the time evolution of the 3 other members of this greenhouse-gas-only forced ensemble (Fig. 10). These evolutions of UK summer climate follow quite different trajectories to the first realisation, with 2 cases generating reductions in UK summer rainfall in certain periods of up to $20 \%$. Two of these realisations enter the 'critical' climate change space by about the 2030s and remain there for most of the rest of the century. It should be remembered that the differences between these 4 individual realisations are not due to different forcings or to different model formulations, but are due solely to the different initial condition of the (model) climate system when the anthro- pogenic greenhouse gas forcing was introduced in 1861. Clearly, much of the difference in rainfall (and temperature) response between these realisations is attributable to natural climate variability. One method for reducing these withinensemble differences is to take an ensemble-mean. This ensemble-mean evolution of UK summer climate is also shown in Fig. 10. A more coherent picture emerges when this is done and the ensemble-mean suggests a summer drying of between 5 and $10 \%$ by the last decades of next century, by which time UK summers would be about $2.5^{\circ} \mathrm{C}$ warmer than now. In the ensemble-mean case, UK summer climate moves into the 'critical' climate change space by about 2060.

The changes in the rainfall dimension of this ensemble-mean time evolution of simulated UK summer climate remain small, however, in relation to observed rainfall variability. This relatively small rainfall signal, particularly when combined with large within-ensemble variability, reinforces the concern expressed earlier about the definition of robust anthropogenic rainfall signals from GCM simulations (cf. Fig. 5 and associated discussion). Depending on which realisation is sampled, and which $30 \mathrm{yr}$ climate is examined within that realisation, the assumed UK summer rainfall change could range from a $19 \%$ drying to a $9 \%$ wetting. This range is almost indistinguishable from the (model-simulated) natural variability of $30 \mathrm{yr}$ averaged rainfall shown in Fig. 5 (or indeed the observed medium-low frequency variability shown in Fig. 3).

A further complication with regard to defining robust anthropogenic signals in rainfall is illustrated when we consider the combined greenhouse gas and aerosol forced ensemble simulations from the same HADCM 2 experiment. Fig. 11 plots the ensemblemean $30 \mathrm{yr}$ filtered time evolution curve shown in Fig. 10, and also the equivalent ensemble-mean curve for the combined forcing simulations. (The individual realisations from the aerosol ensemble are not shown, but have a similar scatter to those shown in Fig. 10 for the greenhouse-gas-only case.) First, note that the eventual summer temperature increase by 2070-2099 is slightly less than the greenhouse-gas-only ensemble-mean (about $0.2^{\circ} \mathrm{C}$ smaller). This is an expected result due to the negative forcing contribution of aerosols. Second, we can see that the rainfall change evolution is quite similar to the greenhouse-gas-only case until the 2050s. After this time, however, summer rainfall in the combined forcing ensemble-mean is 


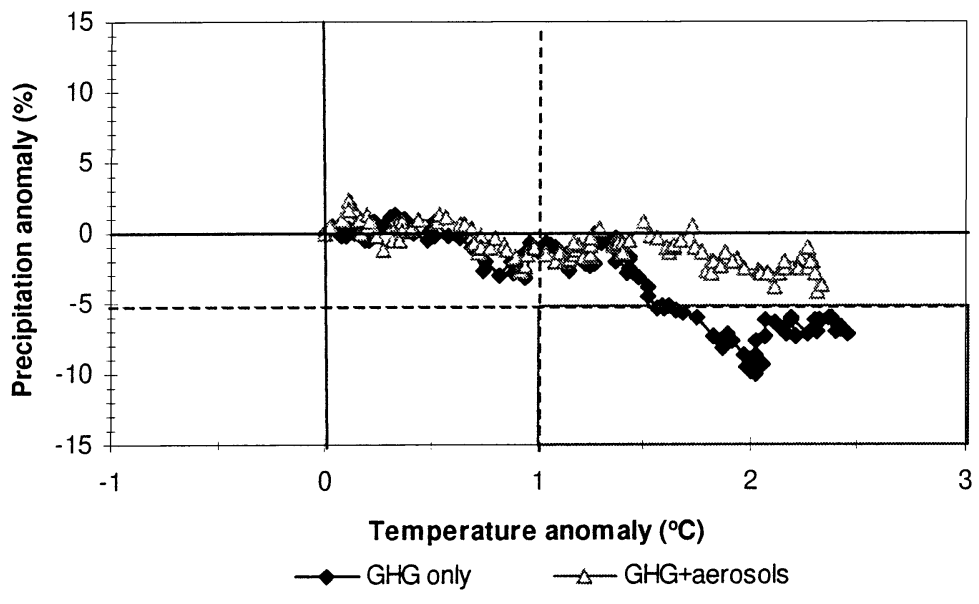

Fig. 11. Time evolution (left to right) of overlapping $30 \mathrm{yr}$ filtered climate anomalies with respect to model-simulated average 1961-1990 climate for 1961-1990 to 2070-2099 for the ensemble-mean of the greenhousegas-only (filled diamonds; cf. Fig. 10) and the combined greenhouse gas and aerosol forced (open triangles) HADCM 2 simulations

likely such a 'critical' change is for UK summer climate? We can first state that observed climate variability over the last $200 \mathrm{yr}$ has not taken us into this 'critical' change space, although there is evidence that over recent decades UK summer climate has been moving in that direction. Second, if we examine the range of GCM simulated equilibrium patterns of climate change, scaled for the year 2050 and assuming mid-range estimates of future forcing and of the climate sensitivity, then the likelihood of 'critical' climate change occurring by this date appears quite small. Third, if we analyse the full IPCC range of future forcings and climate sensitivities, combined with the pattern uncertainties obtained from GCM simulations, then the chances of 'critical' climate change being experienced by 2050 for UK water resources increase. Fourth, on the basis of the HADCM 2 experiment, greenhouse-gas-only forcing is more

maintained at levels only a few per cent below 1961-1990 levels, in contrast to the greenhouse-gasonly forced ensemble-mean in which UK summer dries more rapidly. The combined forcing ensemble-mean remains outside the 'critical' climate change space throughout the twentieth century.

Our final plot in this section combines the results from many of the analyses described above (Fig. 12). The straight lines depict the range of simulated climate changes by 2050, using different estimates for forcing and climate sensitivity, from a sample of GCM experiments. Although all of these climate change realisations exceed historic changes in mean temperature, only a few of them exceed the natural variability of UK summer rainfall, whether this variability is defined from observations or from model simulations. The timefiltered evolving ensemble-mean climate changes from both the greenhouse-gas-only and combined forcing simulations from HADCM 2 pass through this core ' 2050 climate change space' around the middle of next century, although individual realisations of these forcing cases occupy very different parts of the space with respect to summer rainfall changes. By the end of next century both ensemble-mean sets of transient simulations have passed beyond the most likely reaches of the '2050 space', although only in the temperature dimension.

Using our a priori arbitrary definition of 'critical' climate change for UK water resources, what may we conclude about how

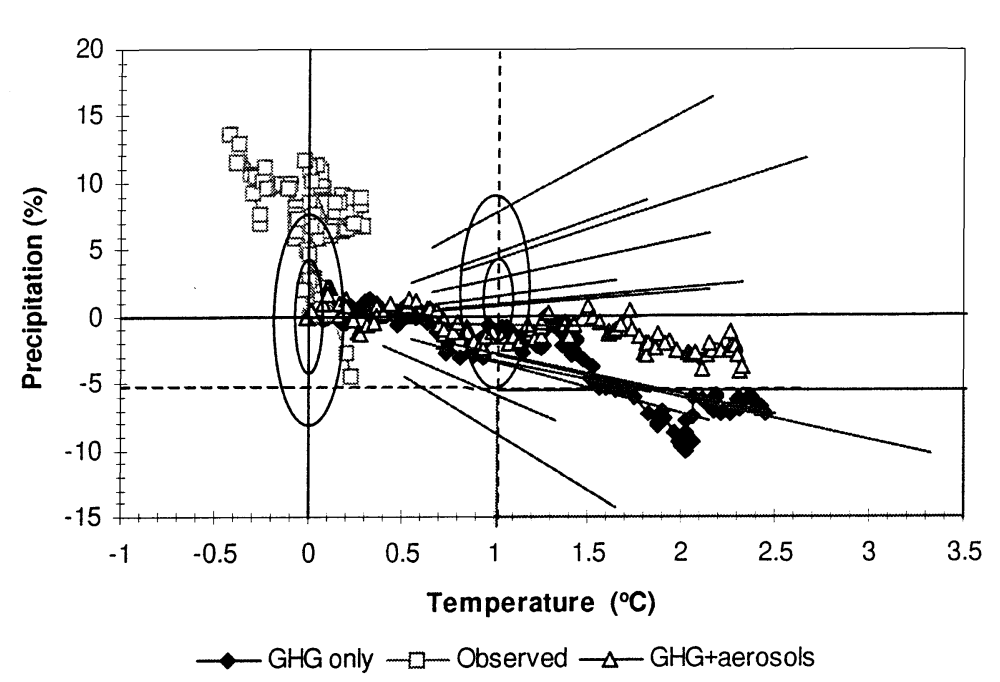

Fig. 12. Superimposition of the data shown in Figs. 7 and 11 likely in the longer term to lead to 'critical' climate change for UK water resources being experienced than the combined effects of greenhouse gases and sulphate aerosols. Finally, and perhaps most important of all, consideration of the range of uncertainties related to the direction and magnitude of future UK summer rainfall change suggests that no robust anthropogenic rainfall signal can be extracted from these model simulations. This is largely a result of the substantial observed and model-generated natural rainfall variability and the relatively small signal-tonoise ratio for anthropogenically forced rainfall change at this regional scale. 

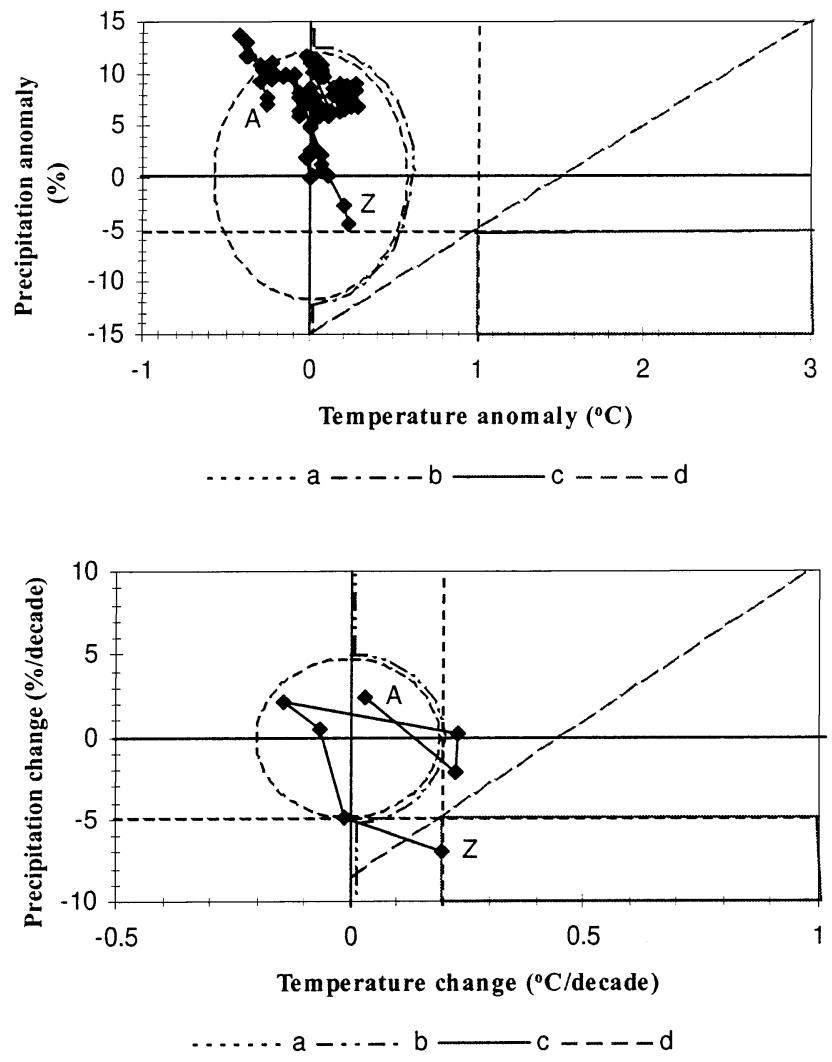

Fig. 13. Alternative representations of critical climate change thresholds for UK water resources using (top) absolute magnitudes of change in mean summer temperature and rainfall and (bottom) decadal rates of change in these 2 variables. These thresholds are chosen arbitrarily to illustrate the range of definitions that could be adopted. The $30 \mathrm{yr}$ filtered climate anomalies for 1896-1925 to 1967-1996 with respect to average 1961-1990 climate are superimposed (cf. Fig. 3a); in the bottom panel they are transformed to display decade-bydecade rates of change. Curves a to $d$ represent alternative definitions of critical climate change limits

\section{DISCUSSION AND CONCLUSIONS}

In this paper we have presented a systematic approach for considering the effect of a set of scenario and modelling uncertainties on the likelihood of critical climate change being exceeded for particular exposure units, and presented this assessment in the context of observed climate change over the last $100 \mathrm{yr}$. We have illustrated the approach for the UK and for a threshold of climate change that may relate, very simplistically, to water resources in the UK. There are a number of considerations that determine the validity of the approach taken here and we discuss some of them below.

The first consideration is the ability to define some critical climate change threshold for a given exposure unit. Parry et al. (1996) outline a number of ways in which such thresholds may be defined, some of which may be more appropriate than others for the analytical approach adopted here. We have deliberately used a very simple example to illustrate our method and other approaches are almost certainly preferable. Carter et al. (1996), for example, use a crop model to explore the relationship between climate scenario uncertainties and critical impact on agriculture in Finland, and some other examples of alternative critical change functions are shown in Fig. 13. These may relate either to absolute thresholds (Fig. 13, top) or to rate of change thresholds (Fig. 13, bottom) being breached. When expressed as a decadal rate of change (Fig. 13, bottom), it is worth noting that recent summer climate in the UK may already be defined as experiencing 'critical' change. Warming has occurred most recently at a rate of $0.2^{\circ} \mathrm{C}$ per decade and drying at a rate of $7 \%$ per decade, an exceedance of thresholds which if persisting over a century would yield a $2^{\circ} \mathrm{C}$ warming and a $50 \%$ drying.

It is also possible to define critical climate change not in terms of mean climates as shown here, but in terms of extremes in interannual variability. Rather than some shift in mean climate from decade to decade, what may be critical is the occurrence of 2 or more successive years which exceed some more extreme annual anomaly threshold such as a $2^{\circ} \mathrm{C}$ temperature anomaly and a $20 \%$ rainfall deficit. The analysis shown here would need to be modified to examine such exceedances, although clearly the interannual data shown in Figs. 2 and 9 would allow such a reworking.

The second issue is the degree to which the scaling of regional GCM-derived patterns of climate change by an independently obtained global warming calculation is justified. This scaling method is used in SCENGEN and lies behind the analysis upon which Figs. 5 and 6 are based. This issue has received little thorough attention in the literature (but see Santer et al. 1990, J onas et al. 1996, Mitchell et al. 1998), although the approach has been adopted in a number of scenario construction and impact assessment studies (e.g. Rotmans et al. 1994, Hulme 1996, Schreider et al. 1996, Schlesinger 1997). It should be noted, however, that similar assumptions about the nature of the anthropogenic climate change signal and its relationship with global-mean temperature change underlie some of the recent climate change detection studies in which model-defined signals are searched for in the observational record using measures of pattern similarity (e.g. Santer et al. 1996).

A third, and related, issue concerns the definition of anthropogenic climate change signals from GCM transient simulations, especially for variables like rainfall which generally have a very low signal-to-noise ratio. As we have shown here from the HADCM 2 experi- 
ment (and for other GCMs), it is hard to argue that any of the simulated ensemble-mean changes in $30 \mathrm{yr}$ mean summer rainfall over the UK are clearly distinguishable from natural variability, whether this variability is defined from the observations or from the control simulation of the model. For individual realisations of a given forcing, rather larger rainfall signals may emerge, but the scatter of these signals as shown in Fig. 10 again casts doubt on whether we are seeing anthropogenic signals as opposed to model-generated natural rainfall variability. For the ensemble-means at least, the introduction of aerosol forcing, in addition to greenhouse gas forcing, prevents UK summer climate from moving into our a priori defined 'critical' climate change space.

This leads on to a fourth consideration that concerns the optimal spatial scale at which the type of analysis described here should be performed. In our example, a restricted spatial domain of about $500 \mathrm{~km}$ has been analysed. It can be argued from a climate modelling perspective that these scales are too small for robust climate information to be extracted from model simulations (von Storch 1995, P. A. Stott \& S. F. B. Tett unpubl.), although this example is typical of the spacescale at which many impacts and vulnerability assessments are performed. It would be a useful exercise to repeat the analysis on a number of expanded spacescales (e.g. 2500 and $5000 \mathrm{~km}$ ) and see whether largely different conclusions would be reached. For example, what level of spatial aggregation, if any, is necessary to establish larger signal-noise ratios for rainfall? The difficulty here is that the larger the spatial scale at which one analyses climate scenarios, the harder it is to relate the outcomes to specific exposure units of national or regional importance.

This scale mis-match is at the heart of problems of climate change impact assessment. If one questions the believability of GCM results at the scale described here, then one either has to up-scale critical change thresholds so that they are applicable on a sub-continental level or else down-scale the GCM results to generate more robust estimates of national or local scale climate change. Certain down-scaling methods could be incorporated into our methodology, although it remains debatable whether down-scaling fundamentally improves the reliability of regional climate change scenarios (Hewitson \& Crane 1996).

A fifth and final consideration concerns the selection of the GCM experiments which are used to define the climate change space in Figs. 5 and 12. The 14 experiments used here include a wide range of experiment dates and model designs. This sel ection, however, does not adequately constitute a controlled statistical sample from which one would ideally wish to define the climate change space. By using ensembles-each con- taining 4 individual realisations-from one set of model experiments we have enlarged this sample somewhat, thus allowing us to quantify crudely the effect of one set of climate change uncertainties. Larger ensemble sizes in the future may allow more statistically valid conclusions to be reached about the range of future regional anthropogenic climate changes. This would move us closer toward one of our desired objectives of being able to quantify the risks of particular climate changes being realised at a regional scale under particular climate forcing scenarios. Ideally, similar large ensembles should be generated for each of a range of forcing scenarios and for each of a number of models with different climate sensitivities. This would allow the full climate change space to be sampled and for each sample to have a distribution of outcomes associated with it.

Acknowledgements. The work described here has been part funded by the European Commission, DGXII (CLIVARA, ENV4-CT0154) and part by the UK Department of the Environment (DoE Contract Number EPG 1/1/14). The interpretation of the data and the views expressed are those of the authors alone. Tom Wigley and Sarah Raper are thanked for access to the MAGICC (Version 2.3) model. SCENGEN (Version 2) has been developed by the Climatic Research Unit under contract to several sponsors. The HADCM 2 data were supplied through the Climate Impacts LINK Project (UK DoE Contract Number EPG 1/1/16). The Hadley Centre supplied updates of the Central England Temperature record and Phil $J$ ones the most recent England and Wales Precipitation values. Tim Osborn, Tim Carter, Tom Wigley and J ohn M itchell supplied helpful comments on an early draft of the paper and the comments of an anonymous reviewer are also acknowledged.

\section{LITERATURE CITED}

Alcamo J , Kreileman E (1996) Emission scenarios and global climate protection. Global Environ Change 6:305-334

Arnell NW, J enkins A, George DG (1994) The implications of climate change for the National Rivers Authority. NRA/HMSO, London

Boer GJ, McFarlene NA, Lazare M (1992) Greenhousegas-induced climate change simulated with the CCC second-generation General Circulation Model. J Clim 5: 1045-1077

Carter TR, Parry ML, Harasawa H, Nishioka S (1994) IPCC technical guidelines for assessing climate change impacts and adaptations. University College London/Center for Global Environmental Research, London/Tsukuba

Carter TR, Saarikko RA, Niemi KJ (1996) Assessing the risks and uncertainties of regional crop potential under a changing climate in Finland. Agric Food Sci Finl 5: 329-350

Cubasch U, Hasselmann K, Höck H, Maier-Reimer E, Mikolajewicz U, Santer BD, Sausen R (1992) Time-dependent greenhouse warming computations with a coupled oceanatmosphere model. Clim Dyn 8:55-69

Dix W, Hunt BG (1995) CSIRO final report to the Department of Environment, Sports and Tourism. CSIRO, Canberra

Hansen J , Lacis A, Rind D, Russell L, Stone P, Fung I, Ruedy 
R, Lerner J (1984) Climate sensitivity analysis of feedback mechanisms. In: Hansen J , Takahashi T (eds) Climate processes and climate sensitivity. Geophysical Monograph No. 29. American Geophysical Union, Washington, DC, p 130-163

Henderson-Sellers A (1996) Can we integrate climatic modelling and assessment? Environ Model Assess 1:59-70

Hewitson BC, Crane RG (1996) Climate downscaling: techniques and application. Clim Res 7:85-95

Hulme M (ed) (1996) Climate change and southern Africa: an exploration of some potential impacts and implications in the SADC region. Climate Research Unit and World Wide Fund for Nature, Norwich

Hulme M, J iang T, Wigley TML (1995b) SCENGEN : a climate change scenario generator. Climatic Research Unit, University of East Anglia, Norwich

Hulme M, Raper SCB, Wigley TML (1995a) An integrated framework to address climate change (ECAPE) and further developments of the global and regional climate modules (MAGICC). Energy Policy 23:347-355

IPCC (1997) An introduction to simple climate models used in the IPCC Second Assessment Report. IPCC Technical Paper II. WM O/UNEP, Geneva

J ohns TC, Carnell RE, Crossley J F, Gregory J M, M itchell J FB, Senior CA, Tett SFB, Wood RA (1997) The second Hadley Centre coupled ocean-atmosphere GCM : model description, spin-up and validation. Clim Dyn 13:103-134

J onas M, Fleschmann K, Ganopolski AV, Krabec J, Sauer U, Olendrzynski K, Petoukhov VK, Shaw RW (1996) Grid point surface air temperature calculations with a fast turnaround: combining the results of IMAGE and a GCM. Clim Change 34:479-512

J ones PD, Conway D (1997) Precipitation in the British Isles: an analysis of area-averaged data to 1995. Int J Climatol 17:427-438

Kattenberg A, Giorgi F, Grass H, Meehl GA, Mitchell J FB, Stouffer RJ, Tokioka T, Weaver AJ, Wigley TML (1996) Climate models-projections of future climate. In: Houghton JT, Meiro Filho LG, Callendar BA, Harris N Kattenburg A, Maskell K (eds) Climate change 1995: the science of climate change. Cambridge University Press, Cambridge, p 285-358

LeggettJ , Pepper WJ , Swart RJ (1992) Emissions scenarios for the IPCC: an update. In: Houghton J T, Callander BA, Varney SK (eds) Climate change 1992: the supplementary report to the IPCC scientific assessment. Cambridge University Press, Cambridge, $\mathrm{p}$ 75-95

Manley G (1974) Central England Temperatures: monthly means 1659 to 1973. Q J R M eteorol Soc 100:389-405

McAvaney BJ, Colman R, Fraser JF, Dhani RR (1991) The response of the BMRC AGCM to a doubling of $\mathrm{CO}_{2}$. BMRC Tech Mem No. 3. Bureau of M eteorology Research Centre, Melbourne

M cGregor J L, Gordon HB, Watterson IG, Dix M R (1993) The CSIRO 9-level atmospheric general circulation model. CSIRO Division of Atmospheric Research Tech Pap No. 26, Mordialloc

Mitchell J FB, Davis RA, Ingram WJ , Senior CA (1995) On surface temperature, greenhouse gases and aerosols: models and observations. J Clim 8:2364-2386

Editorial responsibility: Hans von Storch, Geesthacht, Germany
Mitchell J FB, J ohns TC (1997) On the modification of global warming by sulphate aerosols. I Clim 10:245-267

Mitchell JFB, J ohns TC, Davis RA (1998) Towards the construction of climate change scenarios. Clim Change (in press)

M itchell J FB, Senior CA, Ingram WJ (1989) $\mathrm{CO}_{2}$ and climate: a missing feedback. Nature 341:132-134

Murphy J M, Mitchell J FB (1995) Transient response of the Hadley Centre coupled ocean-atmosphere model to increasing carbon dioxide. Part II. Spatial and temporal structure of response. J Clim 8:57-80

Parker DE, Legg TP, Folland CK (1992) A new daily Central England Temperature series, 1772-1991. Int J Climatol 12: 317-342

Parry ML, Carter TR (1989) An assessment of the effects of climate change on agriculture. Clim Change 15:96-116

Parry ML, Carter TR, Hulme M (1996) What is a dangerous climate change? Global Environ Change 6:1-6

Rotmans J, Hulme M, Downing TE (1994) Climate change implications for Europe: an application of the ESCAPE model. Global Environ Change 4:97-124

Santer BD, Taylor KE, Wigley TML, J ohns TC, J ones PD, Karoly DJ, Mitchell JFB, Oort AH, Penner JE, Ramaswamy V, Schwarzkopf MD, Stouffer RJ, Tett S (1996) A search for human influences on the thermal structure of the atmosphere. Nature 382:39-46

Santer BD, Wigley TML, Schlesinger ME, M itchell J FB (1990) Developing climate scenarios from equilibrium GCM results. M ax Planck Institute for M eteorology, Report No. 47, Hamburg

Schlesinger ME (1997) Geographical scenarios of greenhouse-gas and anthropogenic-sulfate-aerosol induced climate changes. Internal Report, Department of Atmospheric Sciences, University of Illinois, Urbana

Schlesinger ME, Zhao ZC (1989) Seasonal climate changes induced by doubled $\mathrm{CO}_{2}$ as simulated by the OSU atmospheric GCM mixed layer ocean model. J Clim 2:459-495

Schreider SY, J akeman AJ, Pittock AB, Whetton PH (1996) Estimation of possible climate change impacts on water availability, extreme flow events and soil moisture in the Goulburn and Ovens Basin, Victoria. Clim Change 34: 513-546

Smith I , Hulme M (1996) Climate change scenarios, appendix to Chapter 1. In: Feenstra J (ed) Handbook on methods of climate change impacts assessment and adaptation strategies. UNEP/Institute of Environmental Studies, Nairobi

von Storch H (1995) Inconsistencies at the interface of climate impact studies and global climate research. M eteorol Z N F 4:72-80

Wetherald RT, Manabe S (1986) An investigation of cloud cover change in response to thermal forcing. Clim Change 8:5-23

Wigley TML, Raper SCB (1992) Implications of revised IPCC emissions scenarios. Nature 357:293-300

Wigley TML, Richels R, Edmonds J A (1996) Economic and environmental choices in the stabilization of atmospheric $\mathrm{CO}_{2}$ concentrations. Nature 379:240-243

Wilson CA, M itchell J FB (1987) A doubled $\mathrm{CO}_{2}$ climate sensitivity experiment with a global climate model including a simple ocean. J Geophys Res 92:13315-13343

Submitted: J uly 3, 1997; Accepted: J anuary 5, 1998

Proofs received from author(s): February 26, 1998 